\title{
Ineficiência de Acibenzolar-S-Methyl na Indução de Resistência de Feijoeiro Comum à Murcha-de-Curtobacterium*
}

\author{
Rafael M. Soares ${ }^{1 * *}$, Antonio C. Maringoni ${ }^{2}$ \& Giuseppina P.P. Lima ${ }^{3}$ \\ ${ }^{1}$ FEPAGRO Sementes, CEP 98130-000, Júlio de Castilhos, RS, e-mail: rafael-soares@ @epagro.rs.gov.br; ²Departamento de \\ Produção Vegetal, Faculdade de Ciências Agronômicas, UNESP, Cx. Postal 237, CEP 18603-970, Botucatu, SP; \\ ${ }^{3}$ Departamento de Química e Bioquímica, Instituto de Biologia, UNESP, Botucatu, SP
}

(Aceito para publicação em 07/05/2004)

Autor para correspondência: Rafael Moreira Soares

SOARES, R.M., MARINGONI, A.C. \& LIMA, G.P.P. Ineficiência de acibenzolar-S-methyl na indução de resistência de feijoeiro à murchade-Curtobacterium. Fitopatologia Brasileira 29:373-377. 2004.

\begin{abstract}
RESUMO
O efeito da indução de resistência promovido por acibenzolarS-methyl foi avaliado em três cultivares de feijoeiro (Phaseolus vulgaris), com diferentes níveis de resistência à murcha-deCurtobacterium, em dois ensaios distintos, sob condições de casa de vegetação. O primeiro ensaio visou avaliar a ação do acibenzolar-Smethyl na indução de resistência à murcha-de-Curtobacterium e o segundo, objetivou avaliar a ação deste produto na atividade das enzimas peroxidase e polifenoloxidase e no nível de proteínas totais solúveis, em amostras de folhas e caule, sem inoculação do patógeno. Em ambos os ensaios o indutor foi pulverizado na dosagem de $100 \mu \mathrm{g}$ i.a./ml, cinco dias após o transplante das plantas para vasos. $\mathrm{O}$ acibenzolar-S-methyl foi ineficiente, tanto para controlar a doença na

cultivar suscetível (IAC Carioca), quanto para incrementar os níveis de resistência das cultivares resistentes (IAC Carioca Akytã e IAC Carioca Pyatã). A peroxidase apresentou maior atividade nas plantas pulverizadas com o indutor, tanto na folha, como no caule. A polifenoloxidase mostrou maior atividade apenas no caule das plantas pulverizadas. O nível de proteínas totais solúveis foi maior no caule das plantas pulverizadas do que nas não-pulverizadas, porém não diferiu na folha. As enzimas e proteínas avaliadas apresentaram maiores níveis na folha do que no caule das plantas de feijoeiro avaliadas.

Palavras-chave adicionais: Curtobacterium flaccumfaciens, indução de resistência, Phaseolus vulgaris, peroxidase, polifenoloxidase.
\end{abstract}

\section{ABSTRACT}

Inefficiency of acibenzolar-S-methyl in induction of resistance against bacterial wilt in common bean

The effect in the induction of resistance by acibenzolar-S-methyl was evaluated in three common bean (Phaseolus vulgaris) cultivars, with different levels of resistance to bacterial wilt under greenhouse conditions. The first assay evaluated the acibenzolar-S-methyl action in the induction of resistance against bacterial wilt; the second evaluated the action in the peroxidase and polyphenoloxidase activities as well as in total soluble protein level, in leaf and stem, without pathogen inoculation. In both assays, the inducer was sprayed at a dosage of $100 \mu \mathrm{g}$ i.a./ml, five days after transplanting to pots. Acibenzolar-S-methyl was inefficient in controlling the disease in susceptible cultivar (IAC Carioca), nor did it improve the resistance level in resistant cultivars (IAC Carioca Akytã and IAC Carioca Pyatã). Peroxidase showed higher activity in inducer sprayed plants either in leaves or stems. In the sprayed plants, polyphenoloxidase showed higher activity only in stems. The total soluble protein level was higher in the stems of sprayed plants than in those that wern't sprayed, but levels did not differ in the leaves. The enzymes and proteins evaluated showed higher activity and levels in the leaves than in the stems.

\section{INTRODUÇÃO}

Acibenzolar-S-methyl é um produto que interfere nos processos fisiológicos/bioquímicos das plantas, podendo ativar resistência sistêmica aos agentes patogênicos. Esse ingrediente ativo pertence à classe química benzothiadiazole e é o primeiro representante de uma nova categoria de produtos utilizados na proteção de plantas, também chamados de ativadores de plantas ou indutores de resistência (Knight et al., 1997). O

\footnotetext{
* Parte da Tese de Doutorado do primeiro autor. Faculdade de Ciências Agronômicas/UNESP (2001).

**Bolsista da FAPESP
}

mesmo vem sendo avaliado em diversas culturas, entre elas a do feijoeiro (Phaseolus vulgaris L.). Associado a utilização de práticas agrícolas e a aplicação de defensivos químicos tradicionais, este produto é capaz de atender às necessidades de uma agricultura sustentável, com maior produtividade, qualidade e menor impacto econômico e ambiental.

O modo de ação ao nível bioquímico dos produtos descritos como indutores de resistência têm sido estudados em trabalhos recentes (Solorzano et al., 1996; Li \& Li, 1998; Moraes, 1998). A indução pode ocorrer pela ativação de genes que codificam uma série de proteínas relacionadas à patogênese e enzimas envolvidas na síntese de lignina e fitoalexinas, 
como peroxidases e polifenoloxidases (Resende et al., 2000).

Peroxidase e polifenoloxidase são enzimas encontradas em todas as plantas e em muitos fungos e bactérias aeróbicas. Freqüentemente, essas enzimas aumentam sua atividade em resposta ao estresse, e um de seus principais papéis parece ser o de promover a proteção da célula (Siegel, 1993). A relação positiva entre a atividade da peroxidase e a resistência de plantas a doenças, tem sido relatada em diversos trabalhos, sendo que o aumento da atividade da peroxidase durante o desenvolvimento da doença tem se correlacionado com a expressão de resistência em diferentes interações patógenohospedeiro (Hammerschmidt \& Kuc, 1982; Hammerschmidt et al., 1982; Coffey \& Cassidy, 1984).

A bactéria Curtobacterium flaccumfaciens pv. flaccumfaciens (Hedges) Collins \& Jones, agente causal da murcha-de-Curtobacterium, foi constatada pela primeira vez no Brasil, na safra das águas de 1995, no Estado de São Paulo (Maringoni \& Rosa, 1997). Trata-se de um patógeno vascular, transmissível por sementes e de controle restrito, praticamente, através da utilização de cultivares resistentes e de sementes sadias. Essa doença tem ocorrido com freqüência em lavouras de feijoeiro nos Estados de São Paulo, Paraná e Santa Catarina, causando grandes problemas à cultura (Leite Jr. et al., 2001; Maringoni, 2002).

Os objetivos deste trabalho foram: verificar o efeito da aplicação de acibenzolar-S-methyl na indução de resistência à murcha-de-Curtobacterium em três cultivares de feijoeiro com diferentes níveis de resistência a essa doença, assim como avaliar o efeito do indutor na atividade de peroxidase e polifenoloxidase, e no nível de proteínas totais solúveis nas plantas dos cultivares avaliados.

\section{MATERIAL E MÉTODOS}

\section{Ação do acibenzolar-S-methyl no controle da murcha-de- Curtobacterium}

Sementes de feijoeiro dos cultivares IAC Carioca, IAC Carioca Akytã e IAC Carioca Pyatã foram tratadas com hipoclorito de sódio comercial (2,0\% de cloro ativo) a $1 \% \mathrm{em}$ água durante $5 \mathrm{~min}$ e posteriormente lavadas em água corrente. Foram colocadas para germinar em papel-de-filtro sob condições controladas de umidade e temperatura. A metodologia utilizada permite uma germinação mais rápida e a seleção de plântulas com crescimento uniforme para o transplante.

As sementes pré-germinadas foram transplantadas para vasos de 1,0 1 de capacidade (três plântulas/vaso) contendo substrato autoclavado constituído de $70 \%$ de areia grossa, $15 \%$ de terra e $15 \%$ de esterco, sendo posteriormente submetidas a condições de casa de vegetação, a $25 \pm 3{ }^{\circ} \mathrm{C}$, luz natural e irrigados por gotejamento. O indutor de resistência foi pulverizado nas folhas até o início do escorrimento, aos cinco dias após o transplante, na dosagem de $100 \mu \mathrm{g}$ i.a. $/ \mathrm{ml}$, com pulverizador costal da marca Brudden, modelo Super Spray e bico de pulverização do tipo cone vazio.

$\mathrm{O}$ isolado de $C$. flaccumfaciens pv. flaccumfaciens foi inoculado nas plântulas por meio de punção com agulha umedecida em colônia bacteriana desenvolvida em meio nutriente-sacarose-ágar (3,0 g de extrato de carne, 5,0 g de peptona, 5,0 g de sacarose, 1,0 1 de água destilada), a $28^{\circ} \mathrm{C}$, com três dias, em dois pontos na região do caule, acima do nó cotiledonar e abaixo das folhas primárias (Maringoni, 2002). A inoculação foi feita cinco dias após a pulverização com o indutor. O delineamento estatístico utilizado foi o de blocos casualizados, com cinco repetições, no esquema fatorial $3 \mathrm{x}$ 2, com testemunhas não inoculadas (três cultivares $\mathrm{x}$ com ou sem pulverização).

Os sintomas da doença foram avaliados aos 25 dias após a inoculação das plantas, atribuindo-se notas que variam de 0 a 9 , conforme escala para murcha-de-Fusarium adaptada por Maringoni (2002). A massa seca da parte aérea foi avaliada visando estimar a redução do desenvolvimento das plantas.

\section{Análise da atividade de peroxidases, polifenoloxidases e nível de proteínas totais solúveis}

A metodologia de cultivo e pulverização das plantas foi a mesma utilizada no ensaio anterior. $\mathrm{O}$ delineamento estatístico foi o inteiramente casualizado, com quatro repetições, no esquema fatorial 3 x 2 (três cultivares x com e sem pulverização). Foram realizadas quatro coletas de material para análise, aos cinco, dez, 15 e 20 dias após a pulverização com o indutor, cortando-se pedaços do primeiro trifólio da planta e do caule, na região entre o nó cotiledonar e a inserção do primeiro trifólio, obtendo-se, portanto, dois tipos de amostras distintas, da folha e do caule.

As amostras foram processadas para análise da atividade da peroxidase, polifenoloxidase e proteínas totais solúveis, em tampão fosfato $\mathrm{pH}$ 6,7, 0,2 M à temperatura entre $0-4{ }^{\circ} \mathrm{C}$. O homogenado formado foi centrifugado por $15 \mathrm{~min}$ a $10.000 \mathrm{~g}$. A atividade da peroxidase foi determinada de acordo com o método descrito em Lima (1994). A atividade da polifenoloxidase foi determinada pelo mesmo método da peroxidase, com adaptações (Kar \& Mishra, 1976). O teor de proteínas totais solúveis foi determinado pelo método de Bradford (1976).

A análise dos dados foi feita utilizando-se o cálculo das áreas abaixo da curva de progresso da produção dos compostos avaliados, em função do tempo (coletas) (Schneider, 1976), obtendo-se um único valor para cada tratamento, que expressou a atividade do composto durante o período coletado. Os dados foram submetidos à análise de variância.

\section{RESULTADOS E DISCUSSÃO}

Os resultados obtidos evidenciaram que o acibenzolarS-methyl foi ineficiente, tanto para induzir resistência à murcha-de-Curtobacterium na cultivar suscetível, IAC Carioca, como para incrementar os níveis de resistência nas cultivares IAC Carioca Akytã e IAC Carioca Pyatã (Tabela 1). O que se verificou foi que, confirmando resultados obtidos por Maringoni (2002), existe um provável mecanismo de resistência nas cultivares IAC Carioca Akytã e IAC Carioca Pyatã, que dificultou e/ou retardou a colonização dos vasos 
Ineficiência de acibenzolar-S-methyl na indução de resistência de feijoeiro comum...

do xilema pela bactéria.

Analisando os resultados (Tabela 1), pode-se constatar a diferença de reação ao patógeno da cultivar suscetível, IAC Carioca, com severos sintomas da doença nos tratamentos com e sem pulverização, em relação aos dois cultivares com níveis de resistência, que praticamente não apresentaram sintomas da doença. A análise de variância mostrou não haver interação significativa entre os tratamentos e as cultivares.

A massa seca da parte aérea acusou um menor desenvolvimento, na maioria das plantas inoculadas, das cultivares resistentes em relação as não inoculadas, embora não tenham apresentado sintomas severos da doença. Mesmo assim, a redução da massa seca provocada pela inoculação do patógeno na cultivar suscetível foi maior (45,01\%), do que nas cultivares IAC Carioca Akytã (25,34\%) e IAC Carioca Pyatã (27,27\%). Não houve diferença entre a média de redução da massa seca das plantas dos tratamentos pulverizados $(32,88 \%)$ e não pulverizados $(32,20 \%)$ com o indutor de resistência (Tabela 1).

Em feijoeiro, alguns trabalhos têm evidenciado o efeito da aplicação do acibenzolar-S-methyl na redução da severidade dos sintomas do crestamento bacteriano comum, causado por Xanthomonas axonopodis pv. phaseoli Dye (Jesus Júnior et al., 1999). Entretanto, para o patossistema feijoeiro/ Pseudomonas savastanoi pv. phaseolicola Janse a aplicação do acibenzolar-S-methyl não desencadeou o processo de indução de resistência (Siegrist et al., 1997), fato semelhante foi observado no presente trabalho com as diferentes cultivares de feijoeiro inoculadas com C. flaccumfaciens pv. flaccumfaciens.

A análise da peroxidase (Tabela 2) apresentou, na folha, uma maior atividade na cultivar IAC Carioca Akytã em relação a IAC Carioca. A cultivar IAC Carioca Pyatã mostrou atividade intermediária, não diferindo das outras. A atividade da peroxidase no caule foi semelhante nas cultivares de feijoeiro, embora tenha ocorrido tendência da cultivar IAC Carioca Akytã apresentar maior atividade, como constatado na folha. Esta, foi 2,4 vezes maior nas folhas em relação ao caule.

Os tratamentos pulverizados com acibenzolar-Smethyl, tanto na folha como no caule, evidenciaram maior atividade da peroxidase que os não-pulverizados, acusando efeito de indução na produção desta enzima. Essa indução anteciparia prováveis reações bioquímicas de defesa que só seriam ativadas, por exemplo, com o ataque de um patógeno. $\mathrm{O}$ aumento da atividade da peroxidase seria resultante da adaptação das células da planta frente a condições adversas que geram estresse (Gaspar et al., 1985), no caso a aplicação do indutor. Com isso, a planta provavelmente estaria em condições de mostrar resistência contra patógenos aos quais normalmente seria suscetível, embora isso não tenha se confirmado em relação a $C$. flaccumfaciens pv. flaccumfaciens.

A maior atividade da peroxidase na folha da $\mathrm{cv}$. IAC Carioca Akytã pode ser devida à característica de resistência a doenças, como a murcha-de-Curtobacterium, apresentadas por esta cultivar (Maringoni, 2002). Li \& Li (1998) estudaram a atividade da peroxidase em folhas de cultivares de pepino (Cucumus sativus L.) infetadas com Cladosporium cucumerinum Ell. \& Arth e constataram que a atividade foi maior nas cultivares resistentes do que nas suscetíveis. Resultados semelhantes foram observados por Komarova \& Davidovich (1997) em plantas de arroz, cujas cultivares resistentes à ferrugem apresentaram atividade de peroxidase 1,5 a 3 vezes maior que as suscetíveis.

A análise da atividade da polifenoloxidase (Tabela 3) não mostrou, na folha, diferença entre as cultivares e entre os tratamentos com e sem pulverização. No caule não houve diferença entre os cultivares, mas os tratamentos pulverizados mostraram maior atividade dessa enzima que os nãopulverizados. Em média a atividade da polifenoloxidase no

TABELA 1 - Severidade dos sintomas da murcha-de-Curtobacterium e redução na massa seca de três cultivares de feijoeiro (Phaseolus vulgaris) pulverizadas com $100 \mu \mathrm{g}$ i.a./ml de acibenzolar-S-methyl

\begin{tabular}{|c|c|c|c|c|c|c|}
\hline \multirow{2}{*}{ Cultivar } & \multicolumn{2}{|c|}{ Severidade dos Sintomas } & \multirow{2}{*}{ Média } & \multicolumn{2}{|c|}{ Redução na Massa Seca (\%) } & \multirow{2}{*}{ Média* } \\
\hline & Sem pulv. & Com pulv. & & Sem pulv. & Com pulv. & \\
\hline IAC Carioca & 8,67 & 8,50 & $8,58 \mathrm{~A}$ & 50,22 & 39,80 & $45,01 \mathrm{~A}$ \\
\hline IAC Carioca Akytã & 0,47 & 0,60 & $0,53 \mathrm{~b}$ & 21,39 & 29,28 & $27,27 \mathrm{~b}$ \\
\hline IAC Carioca Pyatã & 0,40 & 0,20 & $0,30 \mathrm{~b}$ & 24,99 & 29,56 & $25,34 \mathrm{~b}$ \\
\hline Média* & $3,18 \mathrm{~A}$ & $3,10 \mathrm{~A}$ & & $33,20 \mathrm{~A}$ & $33,88 \mathrm{~A}$ & \\
\hline
\end{tabular}

*Média de cinco repetições. Dados seguidos da mesma letra minúscula na coluna, ou maiúscula na linha, não diferem estatisticamente pelo teste de Tukey a $5 \%$ de probabilidade.

TABELA 2 - Área abaixo da curva de progresso da produção de peroxidase em três cultivares de feijoeiro (Phaseolus vulgaris), com e sem pulverização de acibenzolar-S-methyl

\begin{tabular}{|c|c|c|c|c|c|c|}
\hline \multirow{2}{*}{ Cultivar } & \multicolumn{2}{|c|}{ Severidade dos Sintomas } & \multirow{2}{*}{ Média } & \multicolumn{2}{|c|}{ Redução na Massa Seca (\%) } & \multirow{2}{*}{ Média* } \\
\hline & Sem pulv. & Com pulv. & & Sem pulv. & Com pulv. & \\
\hline IAC Carioca & 3,79 & 5,00 & $4,40 \mathrm{~b}$ & 1,65 & 2,10 & $1,88 \mathrm{a}$ \\
\hline IAC Carioca Akytã & 4,25 & 6,18 & 5,22 a & 2,09 & 2,42 & $2,25 \mathrm{a}$ \\
\hline IAC Carioca Pyatã & 4,07 & 5,11 & $4,59 \mathrm{ab}$ & 1,51 & 2,17 & $1,83 \mathrm{a}$ \\
\hline Média* & $4,04 \mathrm{~B}$ & $5,43 \mathrm{~A}$ & & $1,75 \mathrm{~B}$ & $2,22 \mathrm{~A}$ & \\
\hline
\end{tabular}

*Dados seguidos da mesma letra, minúscula na coluna e maiúscula na linha, não diferem estatisticamente pelo teste de Tukey a 5\% de probabilidade. 
caule foi cerca de nove vezes menor do que na folha.

Ao que tudo indica, a polifenoloxidase está pouco relacionada ao processo de indução de resistência, pois no caule, onde ocorreu a diferença entre os tratamentos, a concentração foi baixa quando comparada com a da folha, levando a supor que essa diferença entre plantas pulverizadas e não-pulverizadas, seja irrelevante no processo de indução de resistência. Resende et al. (2000) não encontraram diferença na atividade da polifenoloxidase em plantas de cacaueiro induzidas pelo acibenzolar-S-methyl, mas mencionaram a possibilidade de terem ocorrido mudanças qualitativas nas isoformas, que não foram possíveis de se medir, ou que as mudanças tenham ocorrido em períodos diferentes das épocas de coleta. As isoformas de enzimas presentes nos vegetais variam tanto quantitativamente, quanto qualitativamente, de acordo com a espécie, o tecido e estádio de desenvolvimento (Galston \& Davies, 1969) ou em função da interação da planta com o ambiente. Além disso, podem ser alteradas por fatores como luz, temperatura, pH e qualquer tipo de estresse (Siegel, 1993).

Os trabalhos sobre a atividade da polifenoloxidase e resistência de plantas, apresentam resultados variados em relação ao papel da enzima, dependendo da cultura e agente indutor utilizado; mas na sua maioria levam a crer que esta enzima, quando comparada com a peroxidase, tem participação secundária no processo de resistência.

Komarova \& Davidovich (1997) não encontraram diferença na atividade da polifenoloxidase entre plantas de arroz com e sem infecção de ferrugem, independente do grau de resistência das cultivares avaliadas e Li et al. (1991) também não observaram relação entre a atividade desta enzima e a resistência de cultivares de amendoim à ferrugem. Por outro lado, Solorzano et al. (1996), estudando a indução sistêmica da peroxidase e da polifenoloxidase, pela aplicação de
$\mathrm{NaH}_{2} \mathrm{PO}_{4}$ em tomateiro, concluíram haver uma relação entre essas enzimas e a resistência. Sendo que a atividade foi maior entre dez e 15 dias, decaindo após 45 dias do tratamento.

O nível de proteínas totais solúveis (Tabela 4) não mostrou, na folha, diferença entre as cultivares, nem entre os tratamentos com e sem pulverização. Foi observado aumento constante e uniforme dos níveis de proteínas em relação ao tempo. Já no caule, não se observou diferença entre os cultivares, mas o tratamento pulverizado diferiu do nãopulverizado, mostrando um aumento no seu nível. A partir da segunda coleta os níveis aumentaram regularmente, e foram, em média, cerca de seis vezes menor no caule que na folha.

$\mathrm{Na}$ literatura são encontrados diversos trabalhos ressaltando o papel de proteínas e glicoproteínas nos mecanismos de resistência das plantas (Linthorst, 1991; Pascholati \& Leite, 1995; Moraes, 1998). Os resultados do presente trabalho, por terem mostrado diferença significativa no nível de proteínas totais solúveis entre tratamentos com e sem pulverização, sugerem haver influência do indutor. Mesmo assim, os resultados não permitiram concluir se ocorreram alterações que seriam relevantes no processo de resistência, pois, além das diferenças terem ocorrido somente no caule, onde os níveis de proteínas totais solúveis foram baixos se comparados à folha, também houve um aumento natural, com o tempo, dos níveis em todos os tratamentos.

As concentrações mais elevadas na folha do que no caule, dos três compostos avaliados, poderiam estar relacionadas com a maior eficiência do acibenzolar-S-methyl na indução de resistência à patógenos que usualmente colonizam as folhas, do que contra patógenos vasculares. Estes últimos, como no caso de C. flaccumfaciens pv. flaccumfaciens, geralmente colonizam os vasos de xilema do caule, e são mais difíceis de serem controlados. Reforçando essa idéia, Bashan (1986) constatou, em plântulas sadias de

TABELA 3 - Área abaixo da curva de progresso da produção de polifenoloxidase em três cultivares de feijoeiro (Phaseolus vulgaris), com e sem pulverização de acibenzolar-S-methyl

\begin{tabular}{|c|c|c|c|c|c|c|}
\hline \multirow{2}{*}{ Cultivar } & \multicolumn{2}{|c|}{ Severidade dos Sintomas } & \multirow{2}{*}{ Média } & \multicolumn{2}{|c|}{ Redução na Massa Seca (\%) } & \multirow{2}{*}{ Média* } \\
\hline & Sem pulv. & Com pulv. & & Sem pulv. & Com pulv. & \\
\hline IAC Carioca & 0,90 & 0,93 & $0,92 \mathrm{a}$ & 0,14 & 0,18 & $0,16 \mathrm{a}$ \\
\hline IAC Carioca Akytã & 0,91 & 0,93 & $0,92 \mathrm{a}$ & 0,15 & 0,16 & 0,16 \\
\hline IAC Carioca Pyatã & 0,94 & 0,86 & $0,90 \mathrm{a}$ & 0,12 & 0,18 & $0,15 \mathrm{a}$ \\
\hline Média* & $0,91 \mathrm{~A}$ & $0,91 \mathrm{~A}$ & & $0,14 \mathrm{~B}$ & $0,17 \mathrm{~A}$ & \\
\hline
\end{tabular}

*Dados seguidos da mesma letra, minúscula na coluna e maiúscula na linha, não diferem estatisticamente pelo teste de Tukey a 5\% de probabilidade.

TABELA 4 - Área abaixo da curva de progresso do nível de proteínas totais solúveis em três cultivares de feijoeiro (Phaseolus vulgaris), com e sem pulverização de acibenzolar-S-methyl

\begin{tabular}{|c|c|c|c|c|c|c|}
\hline \multirow{2}{*}{ Cultivar } & \multicolumn{2}{|c|}{ Severidade dos Sintomas } & \multirow{2}{*}{ Média } & \multicolumn{2}{|c|}{ Redução na Massa Seca (\%) } & \multirow{2}{*}{ Média* } \\
\hline & Sem pulv. & Com pulv. & & Sem pulv. & Com pulv. & \\
\hline IAC Carioca & 239,46 & 274,75 & $257,11 \mathrm{a}$ & 28,59 & 50,18 & $39,37 \mathrm{a}$ \\
\hline IAC Carioca Akytãa & 191,73 & 253,23 & $222,48 \mathrm{a}$ & 27,68 & 38,32 & 33,0 a \\
\hline IAC Carioca Pyatã & 273,60 & 262,09 & $267,85 \mathrm{a}$ & 33,24 & 46,29 & $39,76 \mathrm{a}$ \\
\hline Média* & $234,93 \mathrm{~A}$ & $263,36 \mathrm{~A}$ & & $29,84 \mathrm{~B}$ & $44,92 \mathrm{~A}$ & \\
\hline
\end{tabular}

*Dados seguidos da mesma letra, minúscula na coluna e maiúscula na linha, não diferem estatisticamente pelo teste de Tukey a 5\% de probabilidade. 
Ineficiência de acibenzolar-S-methyl na indução de resistência de feijoeiro comum...

algodoeiro, maiores concentrações de compostos fenólicos em folhas do que no caule e em cultivares resistentes do que em cultivares suscetíveis.

A ineficiência do acibenzolar-S-methyl no controle da murcha-de-Curtobacterium, apesar da constatação de que o produto aumentou a atividade da peroxidase na folha e no caule, e da polifenoloxidase e proteínas totais solúveis no caule das plantas de feijoeiro, poderia indicar que outros mecanismos ou compostos estariam envolvidos na ativação da resistência das plantas neste patossistema. Alguns trabalhos têm demonstrado evidências de que nem todos os genes relacionados com defesa da planta são dependentes da ativação do ácido salicílico, ao qual o acibenzolar-S-methyl é um análogo (Venâncio et al., 2000).

\section{AGRADECIMENTOS}

A FAPESP pela bolsa de estudo concedida.

Ao Conselho Syngenta de Fitopatologistas (Consfit 2002) pelo apoio técnico e financeiro para a realização deste trabalho.

\section{REFERÊNCIAS BIBLIOGRÁFICAS}

BASHAN, Y. Phenols in cotton seedlings resistant and susceptible to Alternaria macrospora. Journal of Phytopathology 116:1-10. 1986.

BRADFORD, M.M. A rapid and sensitive method for the quantitation of microgram quantities of protein utilizing the principle of proteindye binding. Analytical Biochemistry 72:248-254. 1976.

COFFEY, M.D. \& CASSIDY, D.S.M. Peroxidase activity and induced lignification in rusted flax interactions varying in their degree of incompatibility. Canadian Journal of Botany 62:134-141. 1984.

GALSTON, A.W. \& DAVIES, P.J. Hormonal regulation in higher plants. Science 163:1288-1297. 1969.

GASPAR, T., PENEL, C., CASTILLO, F.J. \& GREPPIN, H.A. Two step control of basic and acidic peroxidase and significance for growth and development. Physiologia Plantarum 64:418-423. 1985.

HAMMERSCHMIDT, R. \& KUC, J. Lignification as a mechanism for induced systemic resistance in cucumber. Physiology Plant Pathology 20:61-71. 1982.

HAMMERSCHMIDT, R., NUCKLES, E. \& KUC, J. Association of enhance peroxidase activity with induced systemic resistance of cucumber to Colletotrichum lagenarium. Physiology Plant Pathology 20:73-82. 1982.

JESUS JÚNIOR, W.C., ROMEIRO, R.S., RODRIGUES, F.A. \& PEREIRA, J.L.A. Um derivado benzotiadiazólico como ativador químico de mecanismos de defesa em feijoeiro contra patógenos. Fitopatologia Brasileira 24:293. 1999 (resumo).

KAR, M. \& MISHRA, D. Catalase, peroxidase, and polyphenoloxidase activities during rice leaf senescence. Plant Physiology 57:315-319. 1976.

KNIGHT, S.C., ANTHONY, V.M., BRADY, A.M., GREENLAND, A.J., HEANEY, MURRAY, D.C., POWELL, K.A., SCHULTZ, M.A., SPINKS, C.A., WORTHINGTON, P.A. \& YOULE, D. Rationale and perspectives on the development of fungicides. Annual Review of Phytopathology 35:349-372. 1997.

KOMAROVA, E.P. \& DAVIDOVICH, L.A. Involvement of phenolcarbonic acids and phenol-oxidizing enzymes in rye defense necrotic response to leaf rust infection. Russian Journal of Plant Physiology 44:749-755. 1997.

LEITE JÚNIOR, R.P., MENEGUIM, L. BEHLAU, F., RODRIGUES, S.R. \& BIANCHINI, A. Ocorrência de Curtobacterium flaccumfaciens subsp. flaccumfaciens em feijoeiro no Paraná e Santa Catarina. Fitopatologia Brasileira 26:303-304. 2001 (resumo).

LI, B.J. \& LI, F. Y. Changes in activities and electrophoretic patterns of peroxidase and polyphenoloxidases in cucumbers during infection with Cladosporium cucumerinum. Scientia Agricultura Sinica 31:8688. 1998.

LI, D., WANG, Z.Z. \& LIN, K.H. Relationships between activity of several enzymes and peanut resistance to rust. Journal of South China Agricultural University 12:1-6. 1991.

LIMA, G.P.P. Efeito do cálcio sobre o teor de poliaminas, peroxidase e nitrato redutase em calos de arroz (Oryza sativa L. cv IAC 4440). (Tese de Doutorado). Botucatu. Instituto de Biociências, Universidade Estadual Paulista. 1994.

LINTHORST, H.J.M. Pathogenesis-related proteins of plants. Critical Reviews in Plant Science 10:123-150. 1991.

MARINGONI, A.C. Comportamento de cultivares de feijoeiro comum à murcha-de-Curtobacterium. Fitopatologia Brasileira 27:157-162. 2002.

MARINGONI, A.C. \& ROSA, E.F. Ocorrência de Curtobacterium flaccumfaciens pv. flaccumfaciens em feijoeiro no Estado de São Paulo. Summa Phytopathologica 23:160-162. 1997.

MORAES, M.G. Mecanismos de resistência sistêmica adquirida em plantas. Revisão Anual de Patologia de Plantas 6:261-284. 1998.

PASCHOLATI, S.F. \& LEITE, B. Hospedeiro: mecanismos de resistência. In: Bergamin Filho, A., Kimati, H. \& Amorim, L. (Eds.). Manual de Fitopatologia vol.1. São Paulo, Agronômica Ceres. 1995. pp.444-445.

RESENDE, M.L.V., NOJOSA, G.B.A., AGUILAR, M.A.G., SILVA, L.H.C.P., NIELLA, G.R., CARVALHO, G.A., GIOVANINI, G.R. \& CASTRO, R.M. Perspectivas da indução de resistência em cacaueiro contra Crinipellis perniciosa através do benzotiadiazole (BTH). Fitopatologia Brasileira 25:149-156. 2000.

SCHNEIDER, R.W., WILLIAMS, R.J. \& SINCLAIR, J.B. Cercospora leaf spot of cowpea: models for estimating yield loss. Phytopathology 66:384-388. 1976.

SIEGEL, B.Z. Plant peroxidases - an organismic perspective. Plant Growth Regulation 12:303-312. 1993.

SIEGRIST, L., GLENEWINKEL, D., KOLLE, C. \& SCHMIDTKE, $M$. Chemical induced resistance in green bean against bacterial and fungal pathogens. Zeitschrift fur Pflanzenkrankheiten und Pflanzenschutz 104:559-610. 1997.

SOLORZANO, E., HERNANDEZ, S., FERNANDEZ, E. \& FERNANDEZ, A. Induccion sistemica de peroxidasas y polifenoloxidasas frente a Alternaria solani en tomate por accion del $\mathrm{Na}_{2} \mathrm{PO}_{4}$. Revista de Proteccion Vegetal 11:29-32. 1996.

VENANCIO, W.S., ZAGONEL, J., FURTADO, E.L., SOUZA, N.L. de \& PERES, N.A.R. Novos fungicidas. II - famoxadone e indutores de resistência. Revisão Anual de Patologia de Plantas 8:59-92. 2000. 